\title{
SOME SPECIES OF THE SOUTHEASTERN ITALIAN MIOCENE GIANT GALERICINE DEINOGALERIX (MAMMALIA, EULIPOTYPHLA) REVISITED, WITH REVIEW OF THE GENUS
}

\author{
Andrea Savorelli ${ }^{1} \oplus$, Federico Masini ${ }^{2}$, Antonio Borrani² \& Paul Mazza ${ }^{1} \oplus$ \\ ${ }^{1}$ Dipartimento di Scienze della Terra, Università degli Studi di Firenze 50121, Italy; andrea_savorelli@yahoo.it, paul.mazza@unifi.it \\ ${ }^{2}$ Department of Earth and Marine Sciences (DISTEM), University of Palermo, Via Archirafi 22, Palermo 90123, Italy; federico.masini@ \\ unipa.it, antonio.borrani@unipa.it
}

\author{
KEYWORDS: \\ Deinogalerix; \\ Terre Rosse; \\ late Miocene; \\ Galericini; \\ endemism
}

\section{Bullet-Points Abstract}

- Revision of Deinogalerix remains from the Terre Rosse of Gargano stored at the University of Florence.

- The material was assigned mainly to $D$. freudenthali, $D$. intermedius and $D$. minor.

- The material improves our knowledge of the small and primitive species $D$. freudenthali.

- The study confirms the validity of the lineages $D$. minor-D. brevirostris and $D$. intermedius- $D$. koenigswaldi.

\section{INTRODUCTION}

A careful revision of fossil remains from the Terre Rosse of Gargano (Fig. 1A) stored at the Department of Earth Sciences of Florence improved our knowledge of the genus Deinogalerix Freudenthal, 1972. The aim of this study is clearing the taxonomic status of the specimens and, at the same time, dealing with several issues connected with the evolutionary relationships between the different species.

Freudenthal (1972) described the extremely derived Deinogalerix koenigswaldi Freudenthal, 1972 and Butler (1980) introduced four more species of Deinogalerix, namely: Deinogalerix brevirostris Butler, 1980; Deinogalerix intermedius Butler, 1980; Deinogalerix minor Butler, 1980; and Deinogalerix freudenthali Butler, 1980. Butler (1980) indicated $D$. freudenthali, the smallest species of the genus, as a hypothetical common ancestor of all the other species. He also specified that two lineages emerged from $D$. freudenthali, one passing through the transitional $D$. intermedius and ending to the largest-sized and most-advanced $D$. koenigswaldi; the other passing through $D$. minor and ending up with $D$. brevirostris (which is smaller than $D$. koenigswaldi and coeval with it). Decades later, numerous new finds of Deinogalerix led to the description of another primitive species, Deinogalerix masinii Villier et al., 2013, but also to a questioning of the taxonomic status of $D$. minor and D. intermedius (Villier et al., 2013; Villier \& Carnevale, 2013).

\section{Materials AND Methods}

The studied material comes from infillings ("Terre Rosse") of karstic fissures sampled by the University of Florence and labelled stratigraphically from the oldest to the youngest: F15, F21c, NBS, P81D, F1, F8 and F9.

\section{RESULTS}

The morpho-dimensional analysis performed in this study permits to assign the material from the old fissure F15 to $D$. freudenthali. The newly described specimens considerably improve our knowledge of the species: $D$. freudenthali shares some primitive traits and small size with the better known $D$. masinii (Villier et al., 2013). Nonetheless, a handful of specimens from F15, whose size and morphologic traits somewhat recall $D$. minor from fissure F9, are more difficult to assign to species and suggest the occurrence of a hitherto undetected form; these have therefore been generically indicated as Deinogalerix sp. 1.

P81D produced the richest amount of remains of Deinogalerix of the collection of Florence. Alongside a majority of specimens with typical features of $D$. intermedius, P81D also provided evidence of a species with teeth roughly the size of those of $D$. intermedius but with primitive traits reminiscent of $D$. freudenthali. This further species was here called Deinogalerix sp. 2 .

Fissure F1 and F9 record the occurrence of $D$. intermedius, accompanied by another smaller species; in F1 the latter is attested to only by a fragmental jawbone still preserving $\mathrm{p} 1$, approximately the size of the mandibles of $D$. minor. In F9 the smaller species is represented by a fragmental muzzle still preserving many of its teeth (Fig. 1B-E); it has teeth comparatively less advanced than $D$. brevirostris and comes from a fissure biochronologically older than those in which $D$. brevi-

Corresponding author address: andrea savorelli@yahoo.it

How to cite: Savorelli et al. (2018). Some species of the southeastern Italian Miocene giant galericine Deinogalerix

(Mammalia, Eulipotyphla) revisited, with review of the genus. Fossilia, Volume 2018: 45-47. https://doi.org/10.32774/ FosRepPal.20.1810.144547 
rostris is normally retrieved, therefore it is attributed here to $D$. minor. Fissure F8 is virtually coeval with F9; it yielded a single, slender mandible with features compatible with $D$. intermedius.

Fissures NBS and F21c yielded a small number of specimens. Fissure F21c may likely be contaminated, as indicated in previous literature (Savorelli, 2013): the large-sized and morphologically advanced $\mathrm{p} 4$ retrieved in this deposit could actually belong to either $D$. intermedius or $D$. koenigswaldi and may have been reworked from a more recent fissure filling. In contrast, the single, large-sized and advanced p4 from NBS may be the earliest occurrence of $D$. intermedius in the collection of Florence.

\section{Discussions AND Conclusions}

The analysis performed here broadly confirms and corroborates the framework depicted by Butler (1980); at the same time it shows that the taxonomic revision proposed by Villier et al. (2013) and Villier \& Carnevale (2013), which considered valid species only the primitive $D$. freundenthali and the most derived $D$. koenigswaldi, is less convincing. Based on the new information, $D$. freudenthali joins $D$. masinii as one of the most primitive members of the genus. Nonetheless, $D$. freudenthali is the closest to the hypothetical ancestor of the other species described by Butler (1980). Moreover, in agreement with Butler (1980) and contrary to Villier et al. (2013), the writers find that, similarly to $D$. minor and $D$. intermedius, the divergence between $D$. brevirostris and $D$. koenigswaldi is well apparent. Consequently, the present study strengthens the validity of $D$. minor and $D$. intermedius, as well as the reliability of the phyletic lineages $D$. minor-D. brevirostris and $D$. intermedius- $D$. koenigswaldi. Members of these two lines co-occur at least in the most recent Terre Rosse fissures. Moreover, the new data, alongside recent literature (Savorelli et al., 2017), suggests that two different species of Deinogalerix were constantly present in the faunal assemblages of the Apulia Platform, already since the earliest deposits.

The improved information also complicates the picture: the oldest fissures in fact contain primitive species of unclear taxonomic and phylogenetic status. Indeed, the fossil record of the genus remains imperfect and the many gaps in it do not permit to utter a final word on the origins of the various lines that characterize its evolution. Nonetheless, the remains of Deinogalerix preserved in the Department of Earth Sciences of Florence provide substantial insight into the understanding of the most ancient species of the genus, they bridge the gap of knowledge regarding $D$. minor, and contribute to our understanding of the most ancient representatives of $D$. intermedius. All this new information greatly improves our comprehension of the history of the genus Deinogalerix and, more in general, of the evolutionary dynamics of insular species.

\section{ACKNOWLEDGEMENTS}

We thank the Inspectors of the Archeological Superinten-

Fig. 1. A, location map of localities that yielded the fossils of the Apulia Platform Fauna. B-E, Deinogalerix minor Butler, 1980 from fissure F9, fragmental skull F9-014; B, dorsal view; C, palatal view; D, left lateral view; E, right lateral view.

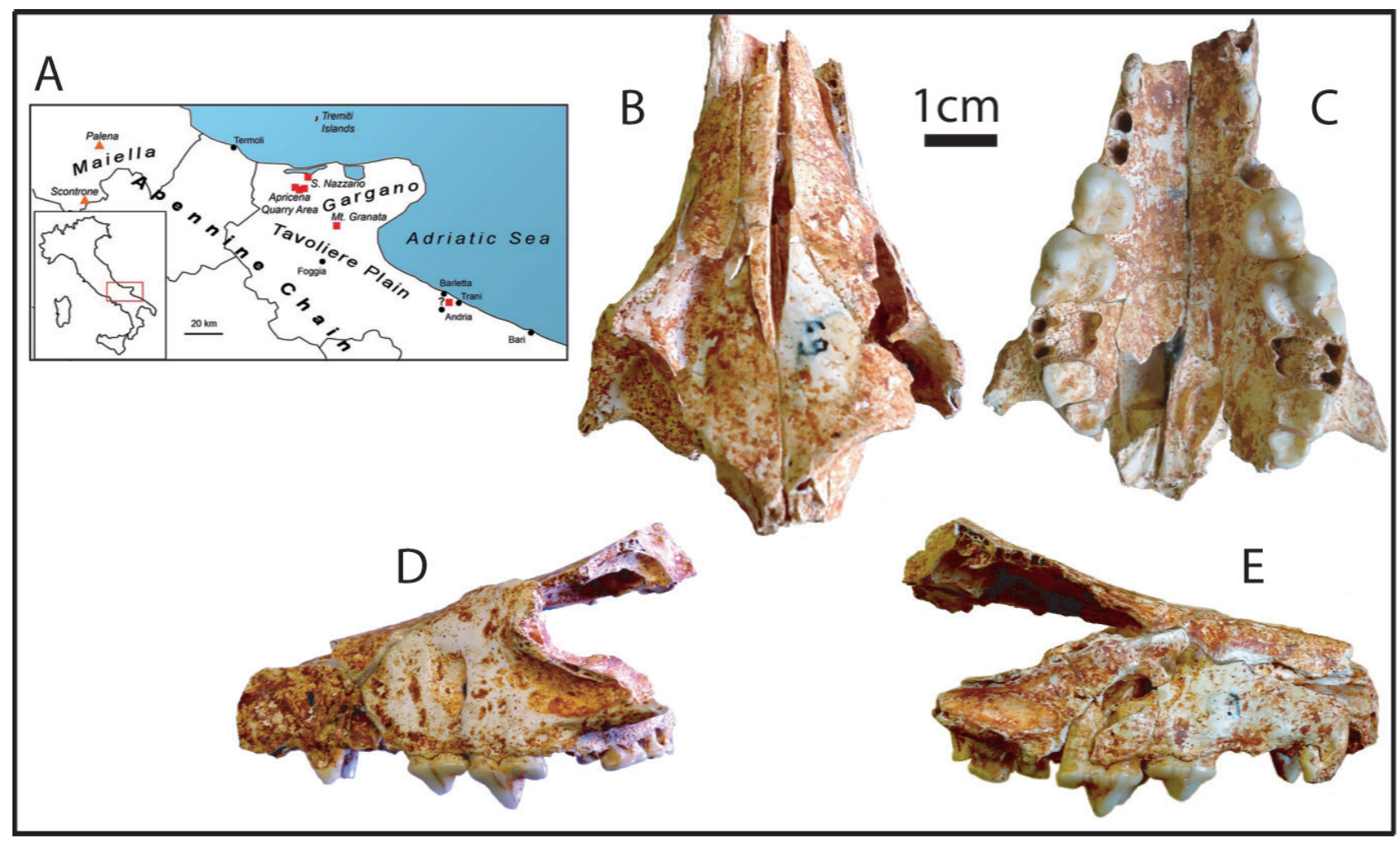


dency of Abruzzo, M.A. Rossi and S. Agostini, for the casts of the Gargano type specimens. We are particularly indebted to M. Pavia, M. Delfino and G. Carnevale for granting us access to the M010 and M013 specimens. PAULMAZZARICATEN15 - Mazza P. Fondo Ateneo 2015 MIUR (the Italian Ministry of Education, University and Research) grants supported this study.

\section{REFERENCES}

Butler P.M. (1980). The giant erinaceid insectivore, Deinogalerix Freudenthal, from the Upper Miocene of Gargano, Italy. Scripta Geologica, 57: 1-71.

Freudenthal M. (1972). Deinogalerix koenigswaldi nov. gen., nov. spec., a giant insectivore from the Neogene of Italy. Scripta Geologica, 14: 1-19.

Savorelli A. (2013). New data on the Cricetidae from the
Miocene "Terre Rosse" of Gargano (Apulia, Italy). Geobios, 46 (1): 77-88.

Savorelli A., Masini F., Mazza P. P. A, Rossi M.A. \& Agostini S. (2017). New species of Deinogalerix (Mammalia, Eulipotyphla) from the late Miocene of Scontrone (Abruzzo, central Italy). Palaeontologia Electronica, 20.1.16A: 1-26.

Villier B. \& Carnevale G. (2013). A new skeleton of the giant hedgehog Deinogalerix from the Miocene of Gargano, southern Italy. Journal of Vertebrate Paleontology, 33 (4): 902-923.

Villier B., Van Den Hoek Ostende L. W., De Vos J. \& Pavia M. (2013). New discoveries on the giant hedgehog Deinogalerix from the Miocene of Gargano (Apulia, Italy). Geobios, 46 (4): 63-75.

Manuscript received 15 July 2018

Received after revision 4 October 2018

Accepted 5 October 2018 